\title{
Colletotrichum gloeosporioides causes anthracnose on grapefruit (Citrus paradisi) in Mexico
}

\author{
Blas Cruz-Lagunas ${ }^{1}$ - Santo Ángel Ortega-Acosta ${ }^{1} \cdot$ Guadalupe Reyes-García ${ }^{1}$. Jeiry Toribio-Jiménez ${ }^{2}$. \\ Porfirio Juárez-López ${ }^{3}$ • Dagoberto Guillén-Sánchez ${ }^{4}$ • Agustín Damián-Nava ${ }^{1}$ • Yanet Romero-Ramírez ${ }^{2}$. \\ Francisco Palemón-Alberto ${ }^{1}$ (D)
}

Received: 9 June 2020 / Accepted: 29 July 2020 / Published online: 1 August 2020

(C) Australasian Plant Pathology Society Inc. 2020

\begin{abstract}
The grapefruit (Citrus paradisi) is an important crop for citrus farming in Mexico. During June 2019, in a plantation in Iguala, Guerrero, Mexico, symptoms of anthracnose on grapefruit fruits were observed. Based on morphological and molecular characterisation, the fungus isolated from the anthracnose was identified as Colletotrichum gloeosporioides. Koch's postulates were verified and fulfilled. To our knowledge, this is the first report of $C$. gloeosporioides causing anthracnose on grapefruit fruits in Mexico.
\end{abstract}

Keywords Causal agent $\cdot$ Fungal disease $\cdot$ Rutaceae $\cdot$ Citrus fruit

The grapefruit (Citrus paradisi) is a subtropical citrus hybrid tree originated in Barbados resulting from an accidental cross (C. maxima and C. sinensis) (Morton 1987). The main grapefruit-producing countries are China, Mexico, South Africa, the United States, and Turkey (FAS 2019). Due to its bioactive compounds, the fruits are utilised in both the pharmaceutical and food industries (Rosa-Hernández et al. 2016). The grapefruit is an important crop for citrus farming in Mexico; 20,918 ha are in production yielding almost 420,000 metric tons of fruits (FAS 2019; SIAP 2019).

In international citrus production, diseases caused by Colletotrichum spp. are among the most important causes of economic losses (Lima et al. 2011; Guarnaccia et al. 2017).

Francisco Palemón-Alberto

alpaf75@hotmail.com

1 Laboratorio de Fisiología y Biotecnología Vegetal, Facultad de Ciencias Agropecuarias y Ambientales, Universidad Autónoma de Guerrero, C.P. 40020, Iguala de la Independencia, Guerrero, Mexico

2 Laboratorio de Microbiología Molecular y Biotecnología Ambiental, Facultad de Ciencias Químico Biológicas, Universidad Autónoma de Guerrero, Av. Lázaro Cárdenas, \#88, El Centenario, CP. 39000, Chilpancingo de los Bravo, Guerrero-México, Mexico

3 Facultad de Ciencias Agropecuarias, Universidad Autónoma del Estado de Morelos, Av. Universidad 1001, 62210 Cuernavaca, Morelos, Mexico

4 Escuela de Estudios Superiores de Xalostoc, Universidad Autónoma del Estado de Morelos, C.P. 62740, Ayala, Morelos, Mexico
During June 2019, in Guerrero, Mexico, in a plantation of grapefruit (about 1.5 ha) in Iguala $(18.359426 \mathrm{~N}$, $99.508297 \mathrm{~W}$ ) symptoms of anthracnose were observed in grapefruit fruits, with an estimated incidence of $15 \%$ in a sample of 120 fruits. Symptomatic fruits developed lightbrown coloured lesions which varied in size, and covered over $50 \%$ of the surface of the fruits. When the disease progressed, lesions with grey aerial hyphae were observed on infected fruits (Fig. 1a). From eight fruits with symptoms, samples of approximately $0.5 \mathrm{~cm}$ in diameter were cut from the advance zone of the lesions. The fragments were superficially disinfested with $1.5 \% \mathrm{NaOCl}$ for $1 \mathrm{~min}$, then rinsed with sterile distilled water, dried with sterile filter paper and transferred to Potato Dextrose Agar (PDA) medium (BIOXON®), and incubated at $25^{\circ} \mathrm{C}$ in the dark for seven days.

The isolated fungus developed colonies that initially had white mycelia, and later turned light grey, with aerial grayishwhite mycelium. Superficial development of orange-coloured conidiomata occurred mainly in the centre of the colony (Fig. 2a). Conidia were unicellular, aseptate, hyaline, cylindrical to oblong with obtuse ends, occasionally slightly curved and measured ( $n=50$ ) 9.7 to $18.5 \times 4.3$ to $5.4 \mu \mathrm{m}$ (length/ width) (Fig. 2b). Based on morphology, the fungus was identified as belonging to the Colletotrichum gloeosporioides species complex (Sutton 1992; Weir et al. 2012). Representative isolates were deposited in the Culture Collection of Plant Pathogenic Fungi of the Department of Plant Physiology and Biotechnology Laboratory at the University 
Fig. 1 Symptoms of anthracnose on grapefruit (Citrus paradisi) caused by Colletotrichum gloeosporioides. Natural symptoms of anthracnose on grapefruit fruit in field conditions (a). Symptoms induced by artificial inoculation with C. gloeosporioides (b). Control fruit (c). Internal lesions caused by $C$. gloeosporioides on artificially inoculated fruit (d). Control fruit (e)

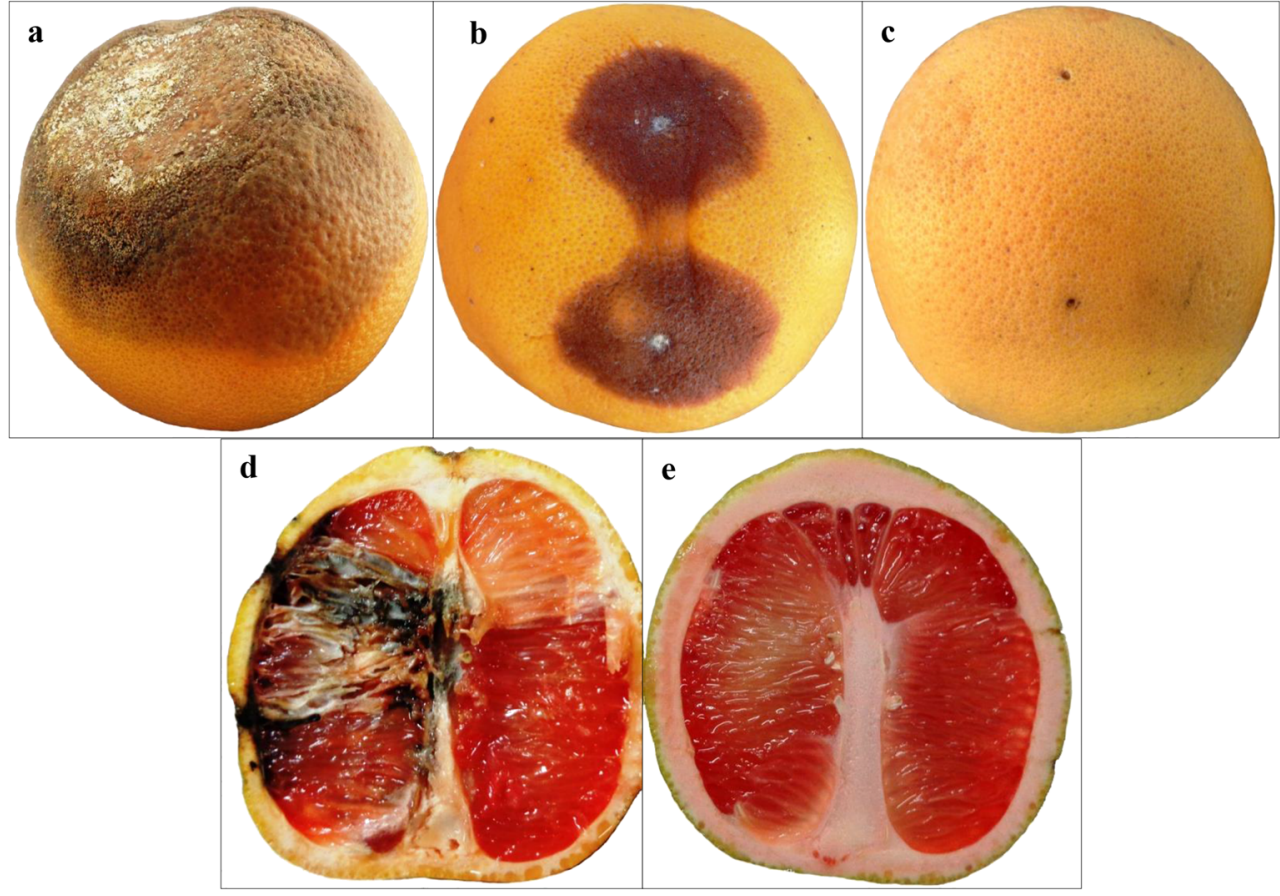

Autonomous of Guerrero (state Guerrero, Mexico), under the accession number COLTOR1 and COLTOR4.

Identification of the fungus was confirmed by comparison of DNA sequences. DNA was extracted from 10-day old cultures of isolates COLTOR1 and COLTOR4 and the internal transcribed spacer (ITS) regions, and partial actin gene (ACT) were amplified with the primers ITS1/ITS4 (White et al. 1990), and ACT-512F/ACT-783R (Carbone and Kohn 1999), respectively, and sequenced by Macrogen, Inc. (Seoul, Korea). BLAST analysis of sequences in GenBank revealed that the ITS and ACT sequences of isolates had $100 \%$ identity with C. gloeosporioides strains (not shown).

Phylogenetic analysis was performed using sequences of ITS and ACT of representative isolates of Colletotrichum (Weir et al. 2012), and sequences of ex-type strains of
C. gloeosporioides were aligned and concatenated in MEGA-X (Kumar et al. 2018). The phylogram tree was obtained using the Neighbor-Joining (NJ) method (Saitou and Nei 1987), and analysed based on the Kimura-2-parameter distance model (Kimura 1980). A bootstrap analysis was realised with 1000 replications of the data using the same program. The phylogram showed that the isolates COLTOR1 and COLTOR4 clustered with the ex-type strains of C. gloeosporioides (CBS 112999 and CBS 953.97) with $99 \%$ bootstrap values (Fig. 3 ).

A pathogenicity test was performed using the COLTOR1 isolate as representative. Asymptomatic grapefruit fruits were washed with running water, then disinfested with a $1 \% \mathrm{v} / \mathrm{v}$ sodium hypochlorite solution for $2 \mathrm{~min}$ followed by two rinses with sterile water, and dried with sterile filter paper. Ten
Fig. 2 Morphological characteristics of Colletotrichum gloeosporioides isolated from anthracnose on grapefruit (Citrus paradisi). Colony on PDA (a) after 7 day of incubation. Conidia (b) of C. gloeosporioides

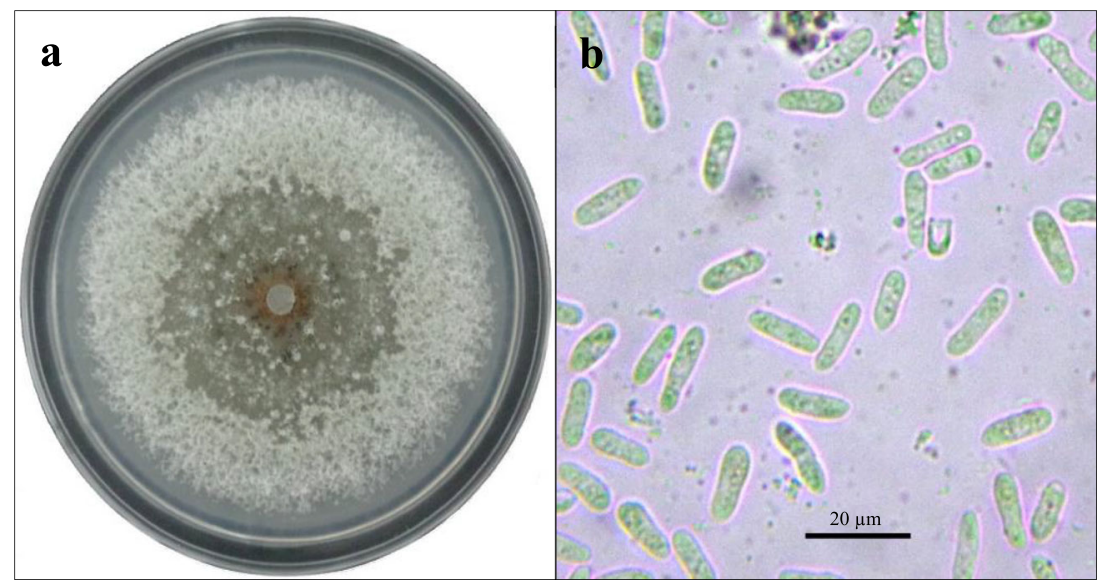


Fig. 3 Phylogram tree using Neighbor-Joining (NJ) method, with analysis based on the Kimura-2-parameter distance model. A bootstrap analysis was conducted with 1000 replications. The phylogram was constructed from a combined dataset of ITS and $\mathrm{ACT}$ sequences showing phylogenetic relationships among Colletotrichum gloeosporioides isolated from grapefruit fruits (COLTOR1 and COLTOR4), and representative species of C. gloeosporioides species complex. Monilochaetes infuscans was used as the outgroup. Species names are followed by culture collection. *CBS $=$ Centraalbureau voor Schimmelcultures, ICMP = International Collection of Microorganisms from Plants, and BRIP = Queensland Plant Pathology Herbarium. **Culture number

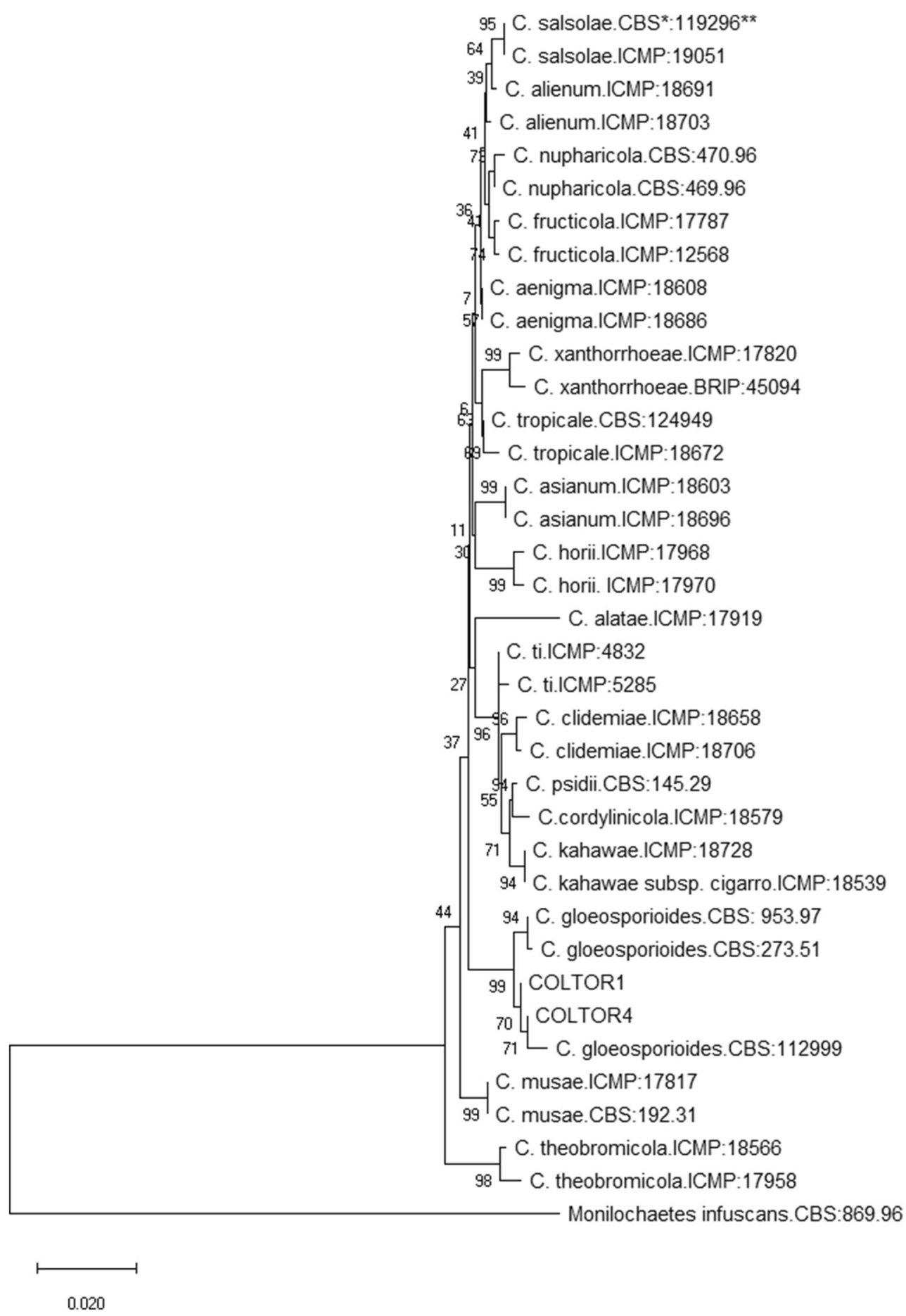

grapefruit fruits were inoculated at two equidistant points/ fruit. A small injury was made with a sterile toothpick ( $2 \mathrm{~mm}$ diameter), and each was inoculated with $10 \mu \mathrm{l}$ of a spore suspension $\left(10^{6}\right.$ conidia/ml). As a control, five grapefruit fruits were inoculated with sterile distilled water. Inoculated fruits were incubated in a closed chamber at $85 \%$ $\mathrm{RH}$ and $28^{\circ} \mathrm{C}$. Fruits of grapefruit inoculated with the COLTOR1 isolate showed typical anthracnose symptoms at all inoculation sites after eight days (Fig. 1b); these symptoms were similar to those observed in the field (Fig. 1a). Artificially inoculated grapefruit fruits developed severe internal necrosis at the inoculated point (Fig. 1d). From these artificially inoculated grapefruit fruits, the causal agent was reisolated and identified morphologically as C.gloeosporioides, thus fulfilling Koch's postulates. The control grapefruit fruits showed no symptoms (Fig. 1c, e). 
In Mexico, there are reports that $C$. acutatum and C. gloeosporioides cause devastating diseases in fruits of Mexican lime (Citrus aurantiifolia) (Ruiz et al. 2014; RojoBáez et al. 2017). In diverse countries such as Australia, Cuba, Italy, Portugal, Sierra Leone, South Africa, Spain,

Trinidad and Tobago, C. gloeosporoides has been reported to cause anthracnose on C. paradisi (Farr and Rossman 2020); but, it had not been reported in Mexico. To our knowledge, this is the first report of $C$. gloeosporioides as causing anthracnose on $C$. paradisi fruits in Mexico (Farr and Rossman 2020). Given the importance of this crop for Mexican citrus farming, this research provides valuable information for the design of effective management for this serious problem for grapefruit field producers.

\section{Compliance with ethical standards}

Conflict of interest The authors declare that they have no conflict of interest.

Ethical approval Experiments do not involve human participants or animals.

\section{References}

Carbone I, Kohn LM (1999) A method for designing primer sets for speciation studies in filamentous ascomycetes. Mycologia 91:553556

Farr DF, Rossman AY (2020) Fungal databases, U.S. National Fungus Collections, ARS, USDA. https://nt.ars-grin.gov/fungaldatabases/. Accessed 15 May 2020

FAS (2019) https://www.fas.usda.gov/. Accessed 5 May 2020

Guarnaccia V, Groenewald JZ, Polizzi G, Crous PW (2017) High species diversity in Colletotrichum associated with citrus diseases in Europe. Persoonia 39:32-50. https://doi.org/10.3767/persoonia. 2017.39.02

Kimura M (1980) A simple method for estimating evolutionary rate of base substitution through comparative studies of nucleotide sequences. J Mol Evol 16:111-120. https://doi.org/10.1007/ bf01731581

Kumar S, Stecher G, Li M, Knyaz C, Tamura K (2018) MEGA X: molecular evolutionary genetics analysis across computing platforms. Mol Biol Evol 35:1547-1549. https://doi.org/10.1093/ molbev/msy096

Lima WG, Sposito MB, Amorim L, Gonçalves FP, Melo de Filho PA (2011) Colletotrichum gloeosporioides, a new causal agent of citrus post-bloom fruit drop. Eur J Plant Pathol 131:157-165. https://doi. org/10.1007/s10658-011-9795-1

Morton JF (1987). Grapefruit, Citrus paradisi. In: Fruits of Warm Climates. NewCROP, New Crop Resource Online Program, Center for New Crops and Plant Products, Department of Horticulture and Landscape Architecture, Purdue University, pp. $152-158$

Rojo-Báez I, Álvarez-Rodríguez B, García-Estrada RS, León-Félix J, Sañudo-Barajas A, Allende-Molar R (2017) Current status of Colletotrichum spp. in Mexico: taxonomy, characterization, pathogenesis and control. Rev Mex Fitopatol 35(3):549-570. https://doi. org/10.18781/r.mex.fit.1703-9

Rosa-Hernández M, Wong-Paz J, Muñiz-Márquez D, Carrillo-Inungaray M, Sánchez-González J (2016) Compuestos fenólicos bioactivos de la toronja (Citrus paradisi) y su importancia en la industria farmacéutica y alimentaria. Rev Mex Cienc Farm 47(2):22-35

Ruiz A, Parra CC, da Graça JV, Salas B, Nsay M, Kunta M (2014) Caracterización molecular y de ensayos de patogenicidad de Colletorichum acutatum, agente causal de la antracnosis del limón en Texas. Rev Mex Fitopatol 32(1):52-61

Saitou N, Nei M (1987) The neighbor-joining method: a new method for reconstucting phylogenetic trees. Molecular Biological Evolution 4: 406-425

SIAP (2019) https://nube.siap.gob.mx/cierreagricola/. Accessed 7 May 2020

Sutton BC (1992) The genus Glomerella and its anamorph Colletotrichum. In: Bailey JA, Jeger MJ (eds) Colletotrichum: biology. Pathology and Control. CAB Int, Wallingford, pp 1-26

Weir BS, Johnston PR, Damm U (2012) The Colletotrichum gloeosporioides species complex. Stud Mycol 73(1):115-180. https://doi.org/10.3114/sim0011

White TJ, Bruns TD, Lee S, Taylor J (1990) Amplification and direct sequencing of fungal ribosomal genes form phylogenetics. In: Innis MA, Gelfrand DH, Sninsky JJ, White TJ (eds) PCR protocols. Academic Press, San Diego, pp 315-322 